\title{
Parasitic Infections, Anemia and Malnutrition Among Rural Settled and Mobile Pastoralist Mothers and Their Children in Chad
}

\author{
M. Bechir, ${ }^{1,2,3}$ E. Schelling, ${ }^{2,3}$ M. A. Hamit, ${ }^{4}$ M. Tanner, ${ }^{2,3}$ and J. Zinsstag ${ }^{2,3}$ \\ ${ }^{1}$ Centre National de Nutrition et de Technologie Alimentaire du Ministère de la Santé Publique au Tchad, BP 440 N'Djamena, Chad \\ ${ }^{2}$ Swiss Tropical and Public Health Institute, P.O. Box 4002, Basel, Switzerland \\ ${ }^{3}$ University of Basel, Petersplatz 1, 4003 Basel, Switzerland \\ ${ }^{4}$ Faculté des Sciences et de la Santé, Université de N’Djamena, BP 1117, N'Djamena, Chad
}

\begin{abstract}
Malnutrition, resulting from various etiologies, is common in rural Chadian women and children. This cross-sectional study assessed the spectrum of parasitic infection and level of anemia and their effect on nutritional status in settled and mobile pastoral mothers and children near Lake Chad. Intestinal parasites were evaluated using direct fecal smears and the Kato-Katz technique. Malaria status was determined using Paracheck-Pf ${ }^{\circledR}$ rapid diagnostic test, and anemia was assessed with the Hemocue photometer. Nutritional status was evaluated using anthropometric parameters. At the end of the 2008 wet season, the prevalence of malnutrition was 36\% [confidence interval (CI) 30-42] among women and 15\% (CI 11-18) among children. The prevalence of intestinal parasitic infection was 75\% (CI 68-83) among women and 60\% (CI 53-66) among children. The predominant helminth species was Ascaris lumbricoides while Entamoeba histolyticaldispar was the most common protozoan. The hookworm prevalence was 14\% (CI 8-20) in women and 18\% (CI 13-23) in children. Malaria prevalence was low among women (1\%, CI 0.5-2) and children (3\% CI 2-5). No significant difference was observed in the prevalence of parasitic infection between the mobile pastoralist and rural sedentary populations. Thirty-four percent (CI 27-40) of nonpregnant women, 53\% (CI 34-72) of pregnant women, and $27 \%$ (CI 23-32) of children were anemic. In subjects infected with Plasmodium, all women and 54\% (CI 2285 ) of children were anemic. Malnutrition was significantly associated with anemia in mothers and with selected intestinal parasites, anemia and age in their children.
\end{abstract}

Keywords: parasitism, malnutrition, anemia, mobile pastoralists, Chad

\section{INTRODUCTION}

Intestinal parasitic infections affect more than two billion people worldwide, with 300 million manifesting clinical signs (WHO 2005). Recent work indicates that morbidity is

Published online: December 13, 2011

Correspondence to: J. Zinsstag, e-mail: jakob.zinsstag@unibas.ch generalized, in particular, iron deficiency anemia, growth stunting, and malnutrition (Hotez et al. 2009), and children between 2 and 5 years of age are particularly vulnerable (Chopra 2006). In developing countries, parasitic infections continue to impact nutritional status causing significant health concerns, especially in children (Chopra 2006). 
In Ethiopian children, $50 \%$ were malnourished, $56 \%$ of whom were infected by intestinal parasites (Worku et al. 2009). Seventy-eight percent of malnourished children were infected with intestinal parasites in Mexico (Quihui-Cota et al. 2004). Hookworm infection and severe anemia were found in $29 \%$ of surveyed people in sub-Saharan Africa (Worku et al. 2009), while high prevalences of malnutrition (50\%) and anemia (75\%) were observed in Zanzibar (Sousa-Figueiredo et al. 2008). Parasitic infections affect the mortality and quality of life of school-aged children, and the suitability of school-based interventions in areas endemic for multiple parasites can be assessed by considering hemoglobin $(\mathrm{Hb})$ and anemia levels (Koukounari et al. 2008). Poverty was exacerbated by high incidence of infectious diseases and the interaction of endemic malaria, malnutrition, and helminthiasis in Indonesia (Lim et al. 2009).

The prevalence of intestinal parasitic infection was $51 \%$ among all age classes for residents in N'Djamena (Hamit et al. 2008), while the prevalence of hookworm infection was $33 \%$ in Chadian school children and $8 \%$ among women in Mali (Brooker et al. 2002; Ayoya et al. 2006). Malaria prevalence varied between 2 and $44 \%$ depending on the season (wet vs. dry) and the population studied (urban N'Djamena residents vs. mobile pastoralists) (Othingué et al. 2006; Schelling et al. 2005). Anemia, the most widespread indicator of nutritional deficiency, was present in $50 \%$ of pregnant women, with $10 \%$ showing severe deficiency. In Chad, rural and mobile pastoralist women were more affected than urban women. Severe anemia was present in more than $10 \%$ of children under 5 years of age (Hamsa et al. 2002; Wyss 1994). In Sahelian Chad, $25 \%$ of women were reported as malnourished, with $19 \%$ of children suffering from acute malnutrition (Ministère de Santé Publique 2007). Poor nutritional status of rural and mobile pastoralist communities is exacerbated by lack of potable water and unsanitary conditions, which contribute to increased parasitic infection rates, particularly among young children and their mothers. This study as part of a larger assessment of nutritional security and vitamin A status in rural Chad (Bechir et al. 2011a, b) aims to improve understanding of parasitic infections and nutritional status by testing the hypothesis that mobile pastoralists, living in close proximity to animals under harsh environmental conditions, are more vulnerable to parasitic diseases and nutritional deficiencies than are rural sedentary communities.

\section{MethOdS}

This cross-sectional study was conducted on the southern shore of Lake Chad, where mobile pastoralist camps are concentrated, and compared mobile pastoralist groups with sedentary communities in a shared pastoral zone (Fig. 1). Data was collected at the end of the 2008 wet season. The sample size was calculated for the estimation of vitamin A deficiency (Bechir et al. 2011b). Two groups of 150 children each were selected based on an assumed prevalence of vitamin A deficiency of $40 \%$ among mobile pastoralist children and $22 \%$ among sedentary children (confidence interval (CI) $95 \%$, power 90\%) (Zinsstag et al. 2004). This allowed detection of minimum odds ratio of 2.2.

The Foulbe and Arabic mobile pastoralist camps were selected randomly within random transects in the study zone as described earlier (Weibel et al. 2008). During camp visits, all children less than 5 years of age and their mothers were enrolled after obtaining informed consent. The sedentary communities were Haoussa, Kanembou, Sara, and Hadjarai living in Baltram, a central village in the study zone. Three village areas were selected from a list of five, using random numbers. In each area, the field team, assisted by the chief of the area and the staff of the local health center, gathered all mothers of children under 5 years of age. The women were briefed and invited to participate in the study. Numbered tickets were distributed to women who were willing to participate. All women received vitamin A capsules and mebendazole. The sedentary group was not further stratified by ethnic group due to small sample sizes.

Pregnant women were identified by female interviewers through specific questions on pregnancy status. Vitamin A capsule distribution assisted further in identification of pregnant women, as health personnel insured that capsules were not given to pregnant women in adherence with the national protocol (Ministère de la Santé Publique 2007). Age of children was assessed with their mothers. For infants, the number of months of breastfeeding was recorded; for children older than 2 years, age was established by number of rainy seasons through which the child lived.

Data was double entered in a database (Access $2003^{\circledR}$, Microsoft, Redmond WA), compared with Epi-Info ${ }^{\text {TM }}$ (version 3.5.1, CDC, Atlanta, GA), and statistically analyzed (Intercooled Stata ${ }^{\circledR}$ 10, College Station, TX). Anthropometric data was transformed in $Z$ scores for children and Body Mass Index (BMI) for women. Binary outcomes and 


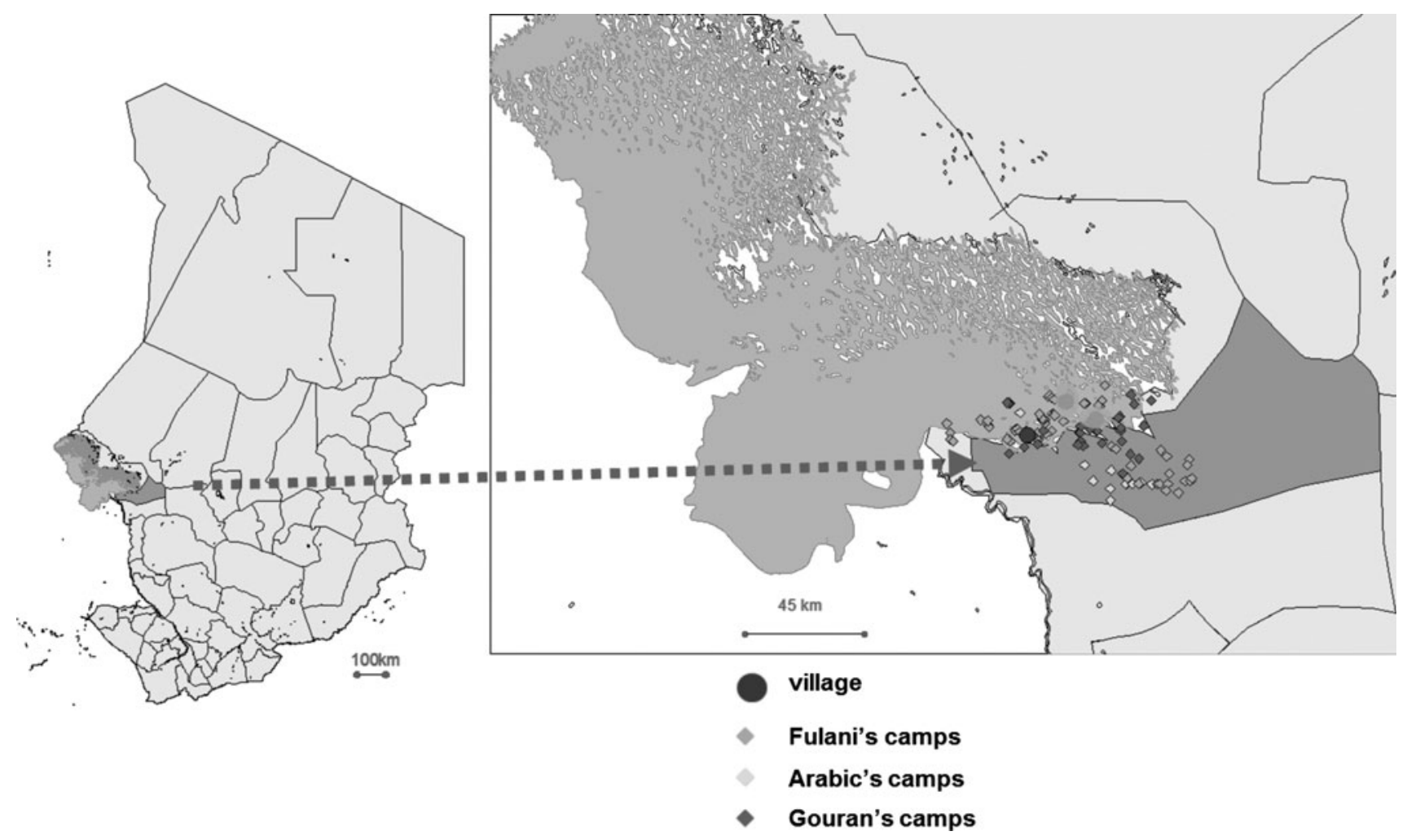

Figure 1. Ecologic map of Chad and study area.

categorical variables were tested with the Chi-square test and continuous outcome variables were tested for differences between groups by analysis of variance. For binary outcomes, in addition to univariable analyses, multivariable logistic regression models were fitted with biologically plausible explanatory variables. Explanatory variables were anemia (binary categorization in anemic and nonanemic), parasitic infection (binary presence/absence of all tested intestinal parasites), age (in months for children and years for women), ethnic group (Foulbe mobile pastoralist, Arab mobile pastoralist, or settled), and sex.

\section{Ethical Considerations}

Ethical clearance was obtained from the Chadian Ministry of Health and the ethics committee of the canton of BaselStadt, Switzerland prior to initiation of the study. On site, regional and local doctors and nurses were informed, and a laboratory technician from the regional hospital and a nurse participated in the field work. All participants were informed about the goals of the study and gave verbal consent prior to the interview. All data was treated confidentially after codification. Vitamin A capsule distribution and mebendazole administration to participants and their relatives were done by qualified health personnel.

\section{Intestinal Parasitic Infections}

The direct fecal smear and Kato-Katz method were used for assessment of intestinal parasites. Tubes for stool collection, marked with unique identification codes, were distributed to each mother. Stool samples were collected during the team's visit in a camp or household and analyzed at a mobile laboratory within $24 \mathrm{~h}$.

\section{Parasitological Tests}

Direct fecal smears enabled observation of protozoal vegetative forms and cysts and helminth eggs and larvae (Gentillini 1993). Microscopic evaluations were performed at $10 \times$ and $40 \times$ as previously described (Lamy 1980; Golvan and Ambroise 1984). The Kato-Katz method was used to quantify helminth eggs. Egg counts in the matrix were adjusted to $1 \mathrm{~g}$ of stool and expressed as eggs per gram of stool (Gentillini 1993; Lamy 1980). Readings were done 15-30 min after preparation, at room temperature (Katz et al. 1972). Malaria was assessed indirectly, using the Paracheck-Pf ${ }^{\circledR}$ rapid immunochromatographic test (Orchid Biomedical System, Goa, India) which detects histidine rich protein-2 antigen to Plasmodium falciparum in blood. The manufacturer's instructions were followed, and results were read after 15 min (Marx et al. 2005). 


\section{Hb Assessment}

The Hemocue ${ }^{\mathrm{TM}}$ Hb301 (Angelholm, Sweden) apparatus was used to assess $\mathrm{Hb}$ levels. A drop of blood was collected aseptically in a microcuvette, which was then placed in the cuvette holder of the device. After approximately $10 \mathrm{~s}$, the $\mathrm{Hb}$ value was displayed. Daily calibration control of the device was done with reference blood. Anemia was defined as $\mathrm{Hb}$ less than $120 \mathrm{mg} / \mathrm{l}$ in nonpregnant women or less than $110 \mathrm{mg} / \mathrm{l}$ in pregnant women and children.

\section{Anthropometric Measurements}

Anthropometric parameters included measurement of height with a tape board and weight with an electronic balance provided by UNICEF. Weight/height index was used for the assessment of acute malnutrition in children, calculating $Z$ scores for each age class and sex (Eq. 1). For women, BMI was calculated (body weight in $\mathrm{kg}$ divided by the square of height in meters). A $Z$ score less than -2 indicated global acute malnutrition for children and a BMI less than $18.5 \mathrm{~kg} / \mathrm{m}^{2}$ indicated malnourishment for women. Results among children were compared to the reference population of the National Centre of Heath and Statistics (Bruce 2003).

$$
Z \text { score }=\frac{\text { Observed value }- \text { Reference value }}{\text { Standard deviation of the reference population }}
$$

\section{Results}

Among 221 women participants, 59 (27\%) were Foulbe mobile pastoralists, 73 (33\%) were Arab mobile pastoralists, and 89 (40\%) were sedentary. Among the 398 children examined, 106 (27\%) were Foulbe, 143 (36\%) were Arab, and $149(37 \%)$ were sedentary.

\section{Parasitic Infections}

The overall prevalence of intestinal parasitic infection was $63 \%$ among women and 60\% among children (Table 1). The difference between women and between children of mobile pastoralist and sedentary communities was not statistically significant. The distribution of parasitic infections in children showed a peak at 24-36 months of age (Table 2). The difference between age groups was statistically significant $(P<0.001)$. Table 3 shows the distribu-
Table 1. Prevalence of parasites in women and children

\begin{tabular}{|c|c|c|c|c|c|c|}
\hline & \multicolumn{3}{|c|}{ Intestinal parasites } & \multicolumn{3}{|c|}{ Plasmodium falciparum } \\
\hline & $N$ & $\%$ & $95 \%$ & $N$ & $\%$ & $95 \%$ \\
\hline & & Prevalence & $\mathrm{CI}$ & & Prevalence & $\mathrm{CI}$ \\
\hline \multicolumn{7}{|l|}{ Women } \\
\hline Foulbe & 42 & 86 & $75-98$ & 73 & 0 & NA \\
\hline Arab & 44 & 68 & $54-83$ & 53 & 3 & $1-8$ \\
\hline Sedentary & 42 & 74 & $60-88$ & 53 & 0 & NA \\
\hline All & 128 & 63 & $55-72$ & 167 & 1 & $0.4-2.8$ \\
\hline \multicolumn{7}{|l|}{ Children } \\
\hline Foulbe & 72 & 58 & $47-70$ & 106 & 5 & $1-8$ \\
\hline Arab & 83 & 60 & $49-71$ & 140 & 2 & $0.5-3$ \\
\hline Sedentary & 60 & 62 & $49-73$ & 137 & 4 & $1-7$ \\
\hline All & 215 & 60 & $53-77$ & 383 & 3 & $1.5-5$ \\
\hline
\end{tabular}

Arab Arab mobile pastoralist, Foulbe Foulbe mobile pastoralist, NA not applicable.

Table 2. Prevalence of intestinal parasitic infection by age group and population in children

\begin{tabular}{lrllll}
\hline Age (months) & $N$ & \multicolumn{3}{l}{ Prevalence (\%) } \\
\cline { 3 - 6 } & & Arab & Foulbe & Sedentary & $\begin{array}{l}\text { All } \\
\text { populations }\end{array}$ \\
\hline $0-6$ & 21 & 14 & 25 & 50 & 28 \\
$>6-12$ & 28 & 50 & 22 & 43 & 39 \\
$>12-24$ & 45 & 55 & 56 & 27 & 49 \\
$>24-36$ & 43 & 81 & 77 & 86 & 81 \\
$>36-48$ & 39 & 77 & 68 & 82 & 74 \\
$>48-59$ & 39 & 62 & 85 & 64 & 67 \\
All ages & 215 & 60 & 58 & 62 & 60
\end{tabular}

Arab Arab mobile pastoralist, Foulbe Foulbe mobile pastoralist.

tion of intestinal parasite species in mobile pastoralist and sedentary women and children. Taenia saginata was particularly prevalent in Foulbe women. Summary prevelances are presented in Table 4. Co-existence of hookworm infection and malnutrition was found in $14 \%$ of women (CI 8-20) and in 18\% of children (CI 13-23). The overall prevalence of $P$. falciparum malaria was low among women and children (Table 3).

\section{Nutritional Status and Anemia}

Malnutrition was found in $36 \%$ of women (CI 30-42) with 55\% (CI 42-68) among Foulbe, 40\% (CI 28-51) among 
Table 3. Proportion and percentage of intestinal parasitic infection by species

\begin{tabular}{|c|c|c|c|c|c|c|c|c|c|c|c|c|c|c|c|c|c|c|}
\hline & \multicolumn{9}{|c|}{ Children } & \multicolumn{9}{|c|}{ Women } \\
\hline & \multicolumn{3}{|c|}{ Foulbe } & \multicolumn{3}{|c|}{ Arab } & \multicolumn{3}{|c|}{ Sedentary } & \multicolumn{3}{|c|}{ Foulbe } & \multicolumn{3}{|c|}{ Arab } & \multicolumn{3}{|c|}{ Sedentary } \\
\hline & $n$ & $\%$ & $95 \% \mathrm{CI}$ & $n$ & $\%$ & $95 \% \mathrm{CI}$ & $n$ & $\%$ & $95 \% \mathrm{CI}$ & $n$ & $\%$ & $95 \% \mathrm{CI}$ & $n$ & $\%$ & $95 \% \mathrm{CI}$ & $n$ & $\%$ & $95 \% \mathrm{CI}$ \\
\hline \multicolumn{19}{|l|}{ Helminths } \\
\hline $\begin{array}{l}\text { Ankylostoma duodenalel } \\
\text { Necator americanus }\end{array}$ & 74 & 20 & $10-29$ & 88 & 25 & $16-35$ & 58 & 5 & $0-8$ & 42 & 26 & $12-40$ & 55 & 15 & $4-24$ & 42 & 2 & $0-7$ \\
\hline Ascaris lumbricoides & 74 & 19 & $9-28$ & 82 & 20 & $11-29$ & 56 & 12 & $2-9$ & 43 & 42 & $26-57$ & 44 & 43 & $27-58$ & 42 & 52 & $36-68$ \\
\hline Taenia saginata & 73 & 0 & NA & 82 & 0 & NA & 56 & 0 & NA & 43 & 21 & $8-33$ & 44 & 0 & NA & 42 & 5 & $0-11$ \\
\hline Schistosoma mansoni & 73 & 0 & NA & 82 & 0 & NA & 56 & 2 & $0-5$ & 43 & 0 & NA & 44 & 2 & $0-6$ & 42 & 0 & NA \\
\hline Hymenolepis nana & 73 & 21 & $11-30$ & 82 & 14 & $6-22$ & 56 & 33 & $22-48$ & 43 & 0 & NA & 44 & 2 & $0-6$ & 42 & 0 & NA \\
\hline \multicolumn{19}{|l|}{ Protozoa } \\
\hline Giardia intestinalis & 73 & 10 & 2.16 & 82 & 23 & $12-31$ & 56 & 3 & $0-8$ & 43 & 12 & $0-21$ & 44 & 23 & $9-36$ & 42 & 0 & NA \\
\hline Trichomonas intestinalis & 73 & 10 & $2-16$ & 82 & 5 & $1-9$ & 56 & 18 & $6-25$ & 43 & 16 & $4-27$ & 44 & 2 & $0-6$ & 42 & 7 & $0-15$ \\
\hline Entamoeba histolytica/dispar & 73 & 34 & $23-45$ & 82 & 36 & $25-47$ & 56 & 23 & $10-32$ & 43 & 26 & $11-39$ & 44 & 50 & $34-65$ & 42 & 36 & $20-50$ \\
\hline
\end{tabular}

Arab Arab mobile pastoralist, Foulbe Foulbe mobile pastoralist, NA not applicable.

Arab, and 20\% (CI 11-28) among sedentary women. In children, acute malnutrition was seen in 15\% (CI 11-18) with 11\% (CI 5-17) among the Foulbe mobile pastoralist, 18\% (CI 12-25) among the Arab mobile pastoralists and 13\% (CI 8-18) among sedentary children. The overall distribution of acute malnutrition by sex of all children is presented in Fig. 2. A tendency of higher levels of malnutrition among mobile pastoralist children was found when compared to sedentary children $(P=0.07)$. For anemia, $34 \%$ (CI 27-40) of nonpregnant women were anemic with $41 \%$ among Foulbe, 37\% among Arabs, and 26\% among sedentary women. Among pregnant women, 30\% had $\mathrm{Hb}$ levels below $110 \mathrm{mg} / \mathrm{l}$. Compared with women, children were less frequently anemic: $27 \%$ overall, with $32 \%$ among Foulbe, 28\% among Arabs, and 23\% among sedentary children.

\section{Association Between Parasitic Infections, Nutritional Status and Anemia}

Higher frequencies of parasitic infections were seen among malnourished women and children compared to those with normal nutritional status. Among malnourished subjects, anemic individuals were more frequently infected with intestinal parasites than those with normal $\mathrm{Hb}$ status $(P<0.01)$ (Table 5).

A multivariable analysis of malnutrition in children as a binary outcome showed that malnourished children were more likely to be anemic $(\mathrm{OR}=3.7)$. Out of the observed parasitic infections, only Hymenolepis nana was significantly associated with malnutrition $(\mathrm{OR}=4.9)$ (Table 6). Among women, only ethnic group $(\mathrm{OR}=2.2$, CI 1.2-3.9) was a significant risk factor for malnutrition.

\section{DISCUSSION}

Intestinal parasitic infections were frequent and high proportions of polyparasitism (more than two infections) were found among women and children. Similar results were observed in Zanzibar, more than 60\% infected (Knopp et al. 2009), and in Côte d'Ivoire, 47\% infected (Scherrer et al. 2009). In children, the observed peak at 24-36 month of age corresponded to the period just after weaning, likely due to ingestion of contaminated soil. Diouf et al. (2000) reported a similar increase after weaning in Senegal. However, Omoigberale and Airauhi (2006) observed peak intestinal parasite infection rates among children between 3 - and 4 years old in Niger.

Hymenolepis nana, A. lumbricoides, and hookworms were the most frequently found helminths among children. A. lumbricoide was the dominant helminth among women, followed by hookworm and T. saginata. For protozoa, Entamoeba histolytica/dispar, Giardia intestinalis, and Trichomonas intestinalis were found in decreasing order among both women and children. Similar proportions were observed in Ethiopia and Senegal. Heresi and Cleary (1997) 
Table 4. Summary prevalence of intestinal parasitic infections by species

\begin{tabular}{lll}
\hline & $\%$ & $95 \% \mathrm{CI}$ \\
\hline Women $(N=129)$ & & \\
Helminths & & \\
Ankylostoma duodenale/Necator americanus & 14 & $8-20$ \\
Ascaris lumbricoides & 45 & $37-54$ \\
Taenia saginata & 8.5 & $3-13$ \\
Schistosoma mansoni & 0.7 & $0-2$ \\
Hymenolepis nana & 0.7 & $0-2$ \\
Protozoa & & \\
Giardia intestinalis & 11.5 & $6-17$ \\
Trichomonas intestinalis & 8.5 & $3-13$ \\
Entamoeba histolytica/dispar & 37 & $28-45$ \\
Children (N = 217) & & \\
Helminths & & \\
Ankylostoma duodenale/Necator americanus & 217 & $12-23$ \\
Ascaris lumbricoides & 217 & $12-22$ \\
Taenia saginata & 217 & $\mathrm{NA}$ \\
Schistosoma mansoni & 217 & $0-1$ \\
Hymenolepis nana & 217 & $16-27$ \\
Protozoa & & \\
Giardia intestinalis & 217 & $8-17$ \\
Trichomonas intestinalis & 217 & $6-14$ \\
Entamoeba histolytica/dispar & 217 & $25-38$ \\
\hline
\end{tabular}

NA not applicable.

suggested that Amoeba and Giardia were part of the natural intestinal flora of people in tropical countries; however, they are likely to be present as a result of poor environmental sanitation.

In this study, T. saginata was found infrequently among children, but the proportion of infection was high (21\%) among Foulbe pastoralist women. This may be due to consumption of dried raw meat (charmout), which is prepared from naturally deceased animals. Further investigations are necessary to confirm the source of human T. saginata infection in mobile pastoralist cattle. Among women in N'Djamena, the prevalence of T. saginata was less than 3\% (Hamit et al. 2008), but Opara et al. (2006) reported a slaughterhouse prevalence of $26 \%$ among cattle in Nigeria. An important proportion of those cattle originated in Chad. This study confirms previous findings in pastoralist cattle associated with brucellosis seroprevalence in the same population (Schelling et al. 2003). Possible zoonotic infection with Mycobacterium bovis which is endemic in cattle in the study population (Diguimbaye-Djaïbe et al. 2006) also

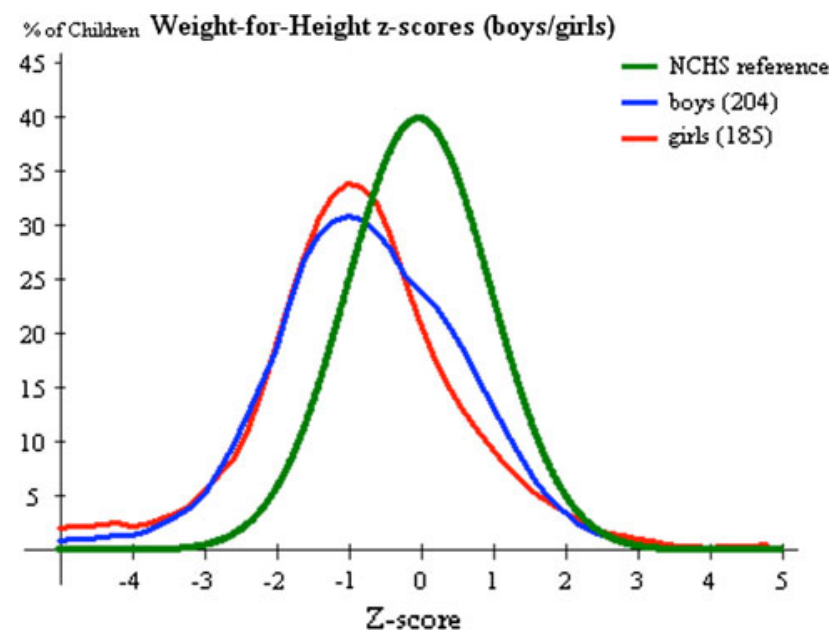

Figure 2. Distribution of acute malnutrition among girls and boys of rural Chad against the NCHS reference.

warrants further investigation. Clearly, there is an active livestock-human interface for the transmission of zoonoses between cattle and humans in Chadian mobile pastoralists which seems specific to their lifestyle and proximity to cattle as compared to sedentary communities in rural and urban zones. A very low prevalence of Schistosoma mansoni was found in this study. This was unexpected, as there is a potentially favorable habitat for snails in the area near Lake Chad.

The observed prevalence of malaria among women and children was low, given that the study was carried out at the end of the wet season and the beginning of the dry season. Othingué et al. (2006) observed similar results with a malaria prevalence of $2 \%$ in urban N'Djamena during the dry season. Conversely, Schelling et al. (2005) found a higher prevalence of clinical malaria $(9 \%)$ in mobile pastoralists in the same study area during the dry season but could not confirm the results with a parasitological test. Malaria was particularly prevalent in camps near or on islands of Lake Chad where mosquito nets were frequently used. The Paracheck-Pf test, used in the current study, has a high level of specificity (95-100\%) and a high sensitivity (88-99\%) (Marx et al. 2005).

The observed high prevalence of parasitic infections among women and children indicates an absence of acquired immunity in adults and a continuous high level of exposure in the studied communities. Likely sources of infections are consumption of contaminated surface water and lack of environmental sanitation (Fig. 3). Women and children infected with intestinal parasites were more anemic than those not infected, reflecting a similar association 
Table 5. Proportion with intestinal parasitic infection according to nutritional and anemia status

\begin{tabular}{|c|c|c|c|c|c|}
\hline & \multirow[t]{2}{*}{$N$} & \multicolumn{4}{|l|}{$\%$} \\
\hline & & $Z$ score $<-2$ & $Z$ score $\geq-2$ & $\mathrm{Hb}<110 \mathrm{mg} / \mathrm{l}$ & $\mathrm{Hg} \geq 110 \mathrm{mg} / \mathrm{l}$ \\
\hline \multicolumn{6}{|l|}{ Children } \\
\hline Arab & 84 & 46 & 63 & 75 & 54 \\
\hline Foulbe & 73 & 83 & 56 & 72 & 52 \\
\hline Sedentary & 60 & 20 & 65 & 63 & 61 \\
\hline \multirow[t]{3}{*}{ All } & 215 & 50 & 61 & 70 & 57 \\
\hline & \multirow[t]{2}{*}{$N$} & \multicolumn{4}{|l|}{$\%$} \\
\hline & & BMI $<18.5 \mathrm{~kg} / \mathrm{m}^{2}$ & $\mathrm{BMI} \geq 18.5 \mathrm{~kg} / \mathrm{m}^{2}$ & $\mathrm{Hb} \quad<120 \mathrm{mg} / \mathrm{l}$ & $\mathrm{Hg} \geq 120 \mathrm{mg} / \mathrm{l}$ \\
\hline \multicolumn{6}{|l|}{ Women } \\
\hline Arab & 41 & 65 & 71 & 79 & 58 \\
\hline Foulbe & 41 & 84 & 86 & 93 & 84 \\
\hline Sedentary & 44 & 71 & 74 & 87 & 71 \\
\hline All & 126 & 74 & 76 & 86 & 71 \\
\hline
\end{tabular}

Arab Arab mobile pastoralist, Foulbe Foulbe mobile pastoralist.

Table 6. Multivariable analysis of potential risk factors for malnutrition in children

\begin{tabular}{lllr}
\hline Children & Odds ratio & $95 \%$ CI & \multicolumn{1}{c}{$P$} \\
\hline Anemia & 3.7 & $1.4-9.9$ & $<0.01$ \\
Ancylostoma duodenalel & 0.9 & $0.2-3.2$ & 0.96 \\
$\quad$ N. americanus & & & \\
Ascaris lumbricoides & 0.6 & $0.2-2.1$ & 0.52 \\
Hymenolepis nana & 4.9 & $1.0-23.6$ & 0.04 \\
Giardia intestinalis & 1.1 & $0.3-4.5$ & 0.80 \\
Trichomonas intestinalis & 2.8 & $0.3-24$ & 0.35 \\
Entamoeba histolytica/dispar & 1.3 & $0.4-3.9$ & 0.62 \\
Age & 0.9 & $0.9-1.0$ & 0.06 \\
Ethnic group & 0.9 & $0.5-1.7$ & 0.80 \\
Sex & 0.5 & $0.2-1.4$ & 0.24 \\
\hline
\end{tabular}

observed by Sousa-Figueiredo et al. (2008) in Tanzania. In this study, a strong association was noted between anemia and hookworms: 80 and 32\% infection rate among anemic women and children, respectively.

Malnutrition was significantly associated with anemia and $H$. nana in children. $H$. nana generally causes fewer clinical signs than hookworm infection; however, it was the most frequent infection in children and may be responsible for negative health outcomes. In Egypt,
H. nana patients showed a significantly higher proportion of altered intestinal permeability than control subjects denoting intestinal leakage, and patients had significantly lower levels of vitamin $B_{12}$ and folate. In addition, the proportions of anemia and malnutrition were higher among $H$. nana patients versus controls (Mohammad and Hegazi 2007).

The analysis of the stool samples was a limitation in this study. The sampling to reading interval was not optimal but was the best that could be achieved under very harsh field conditions. It was not possible to collect repeat samples under these circumstances. The sensitivity of the Kato-Katz method was $70 \%$ for A. lumbricoides with a specificity of $84 \%$. The specificity for hookworms was high (100\%), but the sensitivity was very low (2\%) (Santos et al. 2005).

The most important way to reduce parasitic infections is improved hygiene, especially adequate hand washing which reduces mortality due to diarrhea by as much as $50 \%$, contributing more lives saved than vaccination or other medical intervention (Pittet 2005). The current study did not assess hygienic behavior, but future interventions to improve health status in remote communities should combine access to safer drinking water with effective de-worming and behavioral education programs. 

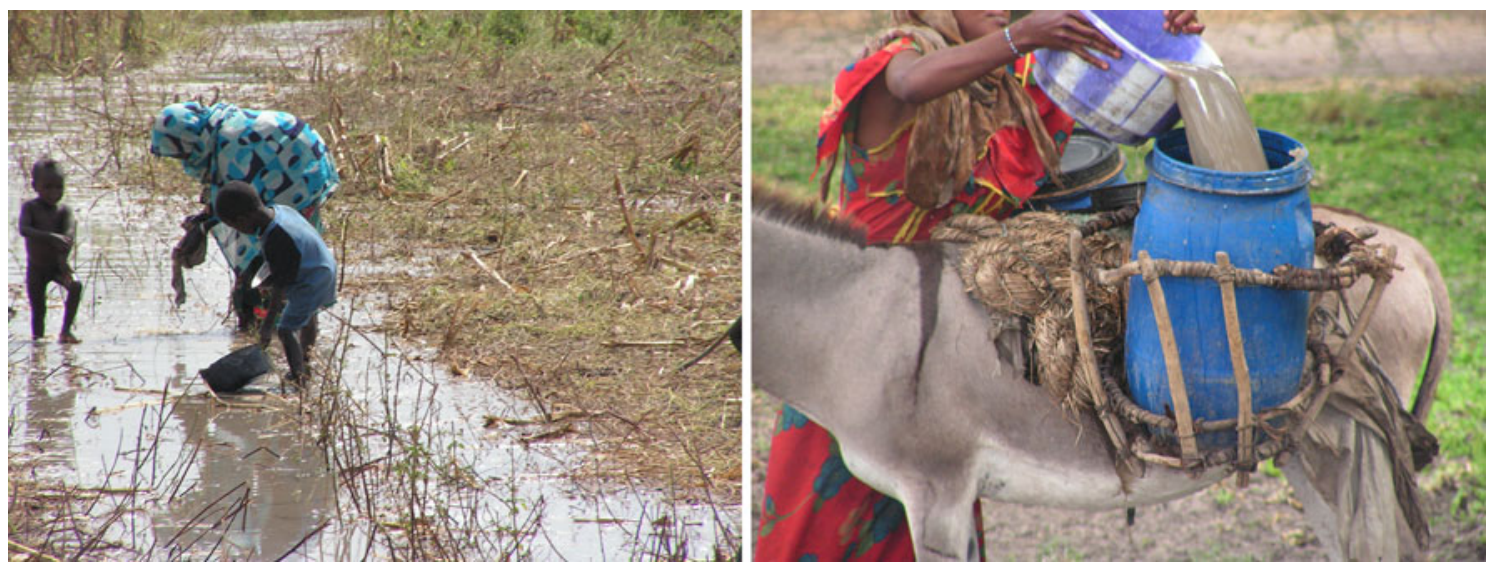

Figure 3. On the left, a mobile pastoralist woman and her children collect surface water for consumption and washing; on the right, collected surface water for consumption and washing is turbid and contaminated with animal and human excreta.

\section{CONCLUSIONS}

In mobile pastoralist and sedentary communities, the frequency of intestinal parasitic infections is high in women and children. A national policy for improved sanitation in rural zones would increase the quality of drinking water. Combining such a policy with better access to basic social services, including education and healthcare, would reduce the prevalence of parasitic infections and anemia and decrease the disease burden on these vulnerable remote communities, particularly among women and children. At the household level, the promotion of community-based sanitation in the sedentary communities and of good hygiene, including regular hand washing and avoiding consumption of raw livestock products, will enhance the effects of such efforts. Access to safe water and environmental sanitation is particularly challenging among mobile pastoralists. Interventions should aim to reduce surface water consumption by providing access to modern wells or locally adapted water treatments. Culturally sensitive behavior modifications to reduce open defecation, such as defecation far from water points and burial of feces, would decrease the level of human pathogens in surface water. A third approach should be directed toward improved personal hygiene, such as fostering hand washing schemes in schools. Mobile pastoralist communities show a trend toward greater levels of malnourishment, but the frequency of parasite infection, except for zoonoses, does not differ between mobile and sedentary lifestyles. Intestinal parasites are a contributing factor in the precarious level of malnutrition in rural Chadian communities warranting integrated approaches to food security including environmental san- itation, health education, and access to safe drinking water. Because mobile pastoralists use semi-arid ecosystems of the Sahel that are not useful for other methods of livestock production, sustainable solutions for food security and human and animal health in rural Chadian communities clearly need to be extended to the whole social-ecological system (Zinsstag et al. 2011).

\section{ACKNOWLEDGMENTS}

This study has been supported by the NCCR North-South funded by the Swiss Development Cooperation and the Swiss National Science Foundation. We thank our partner institutions, the Centre de Support en Santé Internationale and the Laboratoire de Recherches Vétérinaire et Zootechniques in N'Djaména, Chad. We also thank Lisa Crump for assistance with language editing and formatting.

\section{Open Access}

This article is distributed under the terms of the Creative Commons Attribution Noncommercial License which permits any noncommercial use, distribution, and reproduction in any medium, provided the original author(s) and source are credited.

\section{REFERENCES}

Ayoya M, Spiekermann-Brouwer G, Traoré A, Stoltzfus R, Garza C (2006) Determinants of anemia among pregnant women in Mali. Food and Nutrition Bulletin 27:3-11 
Bechir M, Weibel D, Schelling E, Mahamat A, Fokou G, Bonfoh B, Tanner M, Zinsstag J (2011a) Food security among mobile pastoralist and settled communities in Sahelian areas of Chad. EcoHealth (Editorial note: Part of this special feature).

Bechir M, Schelling E, Kraemer K, Schweigert F, Tanner M, Zinsstag J (2011b) Portable vitamin A measurement in mobile pastoralists in Lake Chad area. EcoHealth (Editorial note: Part of this special feature).

Brooker S, Beasley M, Ndinaromtan M, Madjiouroum E, Baboguel M, Djenguinabe E, Hay S, Bundy D (2002) Use of remote sensing and a geographical information system in a national helminth control programme in Chad. Bulletin of the World Health Organization 80:783-789

Bruce C (2003) Guide de Mesure des Indicateurs Anthropométriques, Washington, DC: Food and Nutrition Technical Assistance, pp 104

Chopra M (2006) Mass deworming in Ugandan children. British Medical Journal 333:105

Diouf S, Diallo A, Camara B, Sy Diagne I, Signate H, Sarr M, Fall M (2000) Parasitoses intestinales de l'enfant en zone rurale sénégalaise (Khombole). Médecine d'Afrique Noire 5:229-232

Diguimbaye-Djaïbe C, Hilty M, Ngandolo R, Mahamat H, Pfyffer G, Baggi F, Hewinson G, Tanner M, Zinsstag J, Schelling E (2006) Mycobacterium bovis isolates from tuberculous lesions in Chadian zebu carcasses. Emerging Infectious Diseases 12(5):769-771

Gentillini M (1993) Diagnostic en Parasitologie, 2edn. Paris: Masson.

Golvan Y, Ambroise T (1984) Les Nouvelles Techniques en Parasitologie et Immunoparasitologie, Paris: Flammarion, pp $1-250$

Hamit M, Tidjani M, Bilong C (2008) Recent data on the prevalence of intestinal parasites in N'Djamena, Chad Republic. African Journal of Environmental Science and Technology 2:407411

Hamsa O, Guiral C, Diogoto D, Kémingar N, Diallo P (2002) Enquête national sur l'état nutritionnel et l'alimentation au Tchad. N'Djamena: Ministère de la Santé Publique.

Heresi G, Cleary T (1997) Giardia. Pediatrics in Review 18:243-247

Hotez P, Fenwick A, Savioli L, Molyneux D (2009) Rescuing the bottom billion through control of neglected tropical diseases. Lancet 373:1570-1575

Katz N, Chaves A, Pellegrino J (1972) A simple device for quantitative stool thick-smear technique in Schistosomiasis mansoni. Revista do Instituto de Medicina Tropical de Sao Paulo 14:397-400

Knopp S, Rinaldi L, Khamis I, Stothard J, Rollinson D, Maurelli M, Steinmann P, Marti H, Cringoli G, Utzinger J (2009) A single FLOTAC is more sensitive than triplicate Kato-Katz for the diagnosis of low-intensity soil-transmitted helminth infections. Transactions of the Royal Society of Tropical Medicine and Hygiene 103:347-354

Koukounari A, Estambale B, Njagi J, Cundill B, Ajanga A, Crudder C, Otido J, Jukes M, Clarke S, Brooker S (2008) Relationships between anaemia and parasitic infections in Kenyan schoolchildren: a Bayesian hierarchical modelling approach. International Journal for Parasitology 38:1663-1671

Lamy L (1980) Protozoaires et Helminthes Parasites, Recherche et Identification au Laboratoire, 3 edn. Paris: Maloine.

Lim Y, Romano N, Colin N, Chow S, Smith H (2009) Intestinal parasitic infections amongst Orang Asli (indigenous) in Malaysia: Has socioeconomic development alleviated the problem? Tropical Biomedicine 26:110-122
Marx A, Pewsner D, Egger M, Nüesch R, Bucher H, Genton B, Hatz C, Jüni P (2005) Meta-analysis: accuracy of rapid tests for malaria in travelers returning from endemic areas. Annals of Internal Medicine 142:836-846

Ministère de la Santé Publique (2007) Protocole National de Prise en Charge de la Malnutrition. N’Djamena: Ministère de Santé Publique.

Ministère de Santé Publique (2007) Enquête sur la Situation Nutritionnelle des Enfants de 0 à 59 Mois dans les Régions du Ouaddaï, Wadi Fira, Guéra et Kanem et au sein des Personnes Déplacées. N’Djamena: Ministère de Santé Publique.

Mohammad M, Hegazi M (2007) Intestinal permeability in Hymenolepis nana as reflected by non invasive lactulose/mannitol dual permeability test and its impaction on nutritional parameters of patients. Journal of the Egyptian Society of Parasitology 37:877-891

Omoigberale A, Airauhi L (2006) Aspects of the epidemiology of intestinal parasitoses (IP) in children: knowledge, practices and perceptions of mothers. Nigerian Journal of Clinical Practice 9:109-113

Opara M, Ukpong U, Okoli I, Anosike J (2006) Cysticercosis of slaughter cattle in southeastern Nigeria. Annals of the New York Academy of Sciences 1081:339-346

Othingué NK, Tanner M, Genton B (2006) Urban malaria in the Sahel: prevalence and seasonality of presumptive malaria and parasitaemia at primary care level in Chad. Tropical Medicine and International Health 11:204-210

Pittet D (2005) Clean hands reduce the burden of disease. Lancet 366:185-187

Quihui-Cota L, Valencia M, Crompton D, Phillips S, Hagan P, Diaz-Camacho S, Triana Tejas A (2004) Prevalence and intensity of intestinal parasitic infections in relation to nutritional status in Mexican schoolchildren. Transactions of the Royal Society of Tropical Medicine and Hygiene 98:653-659

Santos F, Cerqueira E, Soares N (2005) Comparison of the thick smear and Kato-Katz techniques for diagnosis of intestinal helminth infections. Revista da Sociedade Brasileira de Medicina Tropical 38(2):196-198

Schelling E, Daoud S, Daugla D, Diallo P, Tanner M, Zinsstag J (2005) Morbidity and nutrition patterns of three nomadic pastoralist communities of Chad. Acta Tropica 95(1):16-25

Schelling E, Diguimbaye C, Daoud S, Nicolet J, Boerlin P, Tanner M, Zinsstag J (2003) Brucellosis and Q-fever seroprevalences of nomadic pastoralists and their livestock in Chad. Preventive Veterinary Medicine 61(4):279-293

Scherrer A, Sjöberg M, Allangba A, Traoré M, Lohourignon L, Tschannen A, N'Goran E, Utzinger J (2009) Sequential analysis of helminth egg output in human stool samples following albendazole and praziquantel administration. Acta Tropica 109: 226-231

Sousa-Figueiredo J, Basáñez M, Mgeni A, Khamis I, Rollinson D, Stothard J (2008) A parasitological survey, in rural Zanzibar, of pre-school children and their mothers for urinary schistosomiasis, soil-transmitted helminthiases and malaria, with observations on the prevalence of anaemia. Annals of Tropical Medicine and Parasitology 102:679-692

Weibel D, Schelling E, Bonfoh B, Utzinger J, Hattendorf J, Abdoulaye M, Madjiade T, Zinsstag J (2008) Demographic and health surveillance of mobile pastoralists in Chad: integration of biometric fingerprint identification into a geographical information system. Geospatial Health 3:113-124 
WHO (2005) Deworming for health and development, Geneva: WHO

Worku N, Erko B, Torben W, Belay M, Kasssu A, Fetene T, Huruy $\mathrm{K}$ (2009) Malnutrition and intestinal parasitic infections in school children of Gondar, North West Ethiopia. Ethiopian Medical Journal 47:9-16

Wyss K (1994) Utilisation des services de santé en milieu urbain à N’Djamena (Tchad): Etude des déterminants et de leurs interactions.

Zinsstag J, Schelling E, Schierle J, Hofmann P, Diguimbaye C, Daugla D, Ndoutamia G, Knopf L, Vounatsou P, Tanner M
(2004) Taux sérique de rétinol chez les femmes mobile pastoralistes pastoralistes tchadiennes en relation avec la teneur en rétinol et en b-carotène dans le lait de leur bétail. Medecine Tropicale 5:478-481

Zinsstag J, Schelling E, Waltner-Toews D, Tanner M (2011) From "one medicine" to "one health" and systemic approaches to health and well-being. Preventive Veterinary Medicine 101(3-4): 148-156 